\title{
Модифицированная модель войны или сражения и гонки вооружения на основе модели Лотки - Вольтерра как модель конфронтации государств: численный и качественный анализ
}

\author{
Т.Г. Возмищева \\ Ижевский государственный технический университет имени М.Т. Калашникова \\ tavo@mail.ru
}

\section{Аннотация}

В работе исследованы модифицированные модели с конкурирующими процессами гонки вооружения - модель Ричардсона, войны или сражения - модель Ланкастера, «хищник-жертва» - на основе модели Лотки - Вольтерра. Проведен качественный анализ, а также численный расчет эволюционных траекторий системы при различных значениях параметров. На основе построенных графиков решений системы дифференциальных уравнений проведен сравнительный анализ классической и модифицированных моделей. Предложенные модифицированные модели Ричардсона и Ланкастера обладают несомненным преимуществом по сравнению с другими моделями. В данной работе в системе дифференциальных уравнений мы учитываем наиболее глобальные и существенные слагаемые: мощность высокоточного и технологического оружия; вступление в эволюционную игру союзников. Динамическое моделирование позволяет определить значения и соотношения параметров, которые в определённый момент времени приводят к перелому войны или сражения.

Отметим, что в статье не рассматриваются реальные конкретные исторические события, так как математические модели всегда ограничены: невозможно учесть, случайные факторы, которые связаны со случайными процессами и носят вероятностный характер.

Получены решения системы дифференциальных уравнений, которые моделируют нелинейное влияние на экосистему как внешних, так и внутренних факторов. Рассмотрены различные параметры системы дифференциальных уравнений, которые охватывают практически весь набор возможного благоприятного и неблагоприятного влияния на эволюцию биоценоза. Приведены условия, для которых при незначительных отрицательных нелинейных слагаемых всё-таки возможно восстановление биоценоза.

Ключевые слова: модель Лотки - Вольтерра, модель Ланкастера войны или сражения, модифицированная модель Ланкастера, модель Ричардсона гонки вооружения, модифицированная модель «хищник-жертва».

Библиографическая ссылка: Возмищева Т.Г. Модифицированная модель войны или сражения и гонки вооружения на основе модели Лотки - Вольтерра как модель конфронтации государств: численный и качественный анализ // Информационное общество: образование, наука, культура и технологии будущего. Выпуск 4 (Труды XXIII Международной объединенной научной конференции «Интернет и современное общество», IMS-2020, Санкт-Петербург, 17 - 20 июня 2020 г. Сборник научных статей). - СПб: Университет ИТМО, 2020. С. 72-91. DOI: $10.17586 / 2587-8557-2020-4-72-91$ 


\section{Введение}

История человечества пронизана войнами и вооружёнными конфликтами (вооружённый конфликт характеризуется, в отличие от войны, ограниченностью целей). В современном мире в новостных блоках также присутствует описание войн и вооруженных конфликтов как внутри отдельных государств, так и между государствами. Основная борьба между государствами разворачивается за экономическую и политическую гегемонию. В связи с этим идёт гонка вооружений, а современное вооружение тесно связано с развитием науки. Системы дифференциальных уравнений, описывающие реальные, совершенно различные явления в физике, механике, политике, биологии и других областях могут быть тесно связаны между собой. Их эволюция зачастую основана на конкурирующих процессах. В данной работе мы рассмотрим следующие явления: гонки вооружения на основе модели Ричардсона; войны или сражения на основе модели Ланкастера; динамики системы «хищник-жертва». Так как эволюция рассматриваемых моделей является результатом конкуренции, основой математического моделирования служит система Лотки - Вольтерра $[1,2,3]$. Предложенная тема чрезвычайно интересна, так как качественный и численный анализ моделей реальных процессов определяет не только тенденцию эволюции систем дифференциальных уравнений, но и результат: бесконечная гонка вооружений или взаимное разоружение; победа или поражение в войне; благополучное существование биоценоза или образование мёртвых зон.

Существуют различные модели эволюции биоценоза: модель Лотки - Вольтерра; Колмогорова; Холлинга - Тэннера; Розенцвейга - Макартура и др. В данной работе мы рассматриваем модифицированную модель Лотки - Вольтерра.

Математическая модель Лотки - Вольтерра, также она называется моделью «хищникжертва», применяется для описания эволюционных процессов в различных областях человеческой деятельности, в частности, в биологии, экологии, экономике, социологии, медицине, истории, информатике. Приведем несколько примеров: модель военных конфликтов; модель классовой борьбы; модель распространения эпидемий; модель выравнивания цен на товары, модель заражения вирусом компьютеров. На самом деле, на основе модели Лотки - Вольтера можно рассматривать все модели, где присутствуют конкурентные отношения между исследуемыми объектами.

Представленная модель, задается системой дифференциальных уравнений, описывающей конкурирующие процессы, в которой используются параметры, а не функциональные зависимости коэффициентов. Благодаря компьютерному моделированию, мы можем учитывать большое количество значений параметров и их комбинаций. Таким образом, становится очевидным влияние внешних и внутренних факторов на экосистему, можно также выделить их негативное и позитивное влияние на эволюцию.

Отметим, что в статье не рассматриваются реальные конкретные исторические события и экологические системы, так как математические модели всегда ограничены: невозможно учесть все случайные факторы, которые связаны со случайными процессами и носят вероятностный характер [4, 5]. Предложенные модифицированные модели являются детерминистическими, такие модели не могут точно описывать реальные явления, однако дают возможность выделить наиболее важные факторы влияния на эволюцию и определить характер развития систем в глобальном смысле. Учёт вероятностного характера всех случайных процессов значительно усложняет математическую модель.

Таким образом, никакого противоречия нет, поскольку исследуются детерминистические математические модели, которые имеют как преимущества, так и недостатки по сравнению со стохастическими моделями, которые также имеют свои преимущества и недостатки. Детерминистические модели дают возможность с помощью информационных технологий (численный расчёт) выявить и провести анализ глобальных тенденций эволюции систем. Стохастические же модели предполагают очень громоздкий 
математический аппарат и дают возможность смоделировать возможно одно конкретное историческое событие. Так что мы должны пройти между Сциллой и Харибдой, и нам это удалось в данной постановке задачи благодаря компьютерному моделированию.

Преимуществом математического моделирования с использованием информационных технологий является возможность анализа влияния параметров и их различных комбинаций на эволюцию систем, построение эволюционных графиков и их анализ. Таким образом, мы можем выявить определённые закономерности эволюции и избежать негативного развития [6, 7].

В работе мы исследуем следующие три случая.

1. Модель Ричардсона, определяющая агрессивность или миролюбивость политики государств, соответственно недовольство проводимой политикой их населения. В данной модели основной целью эволюции является суверенитет, сохранение границ государств. Чтобы обезопасить себя, государство стремится нарастить свой военный потенциал, для этого необходимо развивать научные разработки именно в области современного вооружения и освоения космоса с точки зрения его использования в давлении на другие государства. В результате такой политики государство либо наращивает, либо снижает гонку вооружений. Предельными случаями являются бесконечная гонка вооружений $[8,9]$ или взаимное разоружение. Конкурирующие процессы - агрессивное и миролюбивое развитие ситуации.

2. Война или сражение на основе модифицированной модели Ланкастера. Цель государств - победа и завоевание контроля над противником, негативным результатом является поражение. Конкурирующие процессы - противостояние армий противников.

3. Модель «хищник-жертва» на основе модифицированной модели Лотки - Вольтерра. Конкурирующие процессы - жертвы плодятся пропорционально своей численности, численность жертв сокращается из-за поедания хищниками, а последние, напротив, плодятся, при недостаточном количестве пищи хищники вымирают. Предельным случаем эволюции данной системы является вымирание и жертв, и хищников, то есть образование мёртвых зон.

Для численного анализа и построения графиков решений системы дифференциальных уравнений, описывающих исследуемые модели, используется математический пакет Maple. Данный пакет является одним из наиболее надёжных и достаточно простых инструментов для реализации и визуализации любого исследования, где используется математика. В данном случае используется метод Рунге - Кутта - Фельберга 4(5) порядка (установлен по умолчанию).

\section{1. Модель Ричардсона «гонка вооружений»}

\section{1. Постановка задачи}

Исследуем первый случай, когда два государства находятся в состоянии конфронтации. Модель Ричардсона «гонка вооружений» описывается системой дифференциальных уравнений

$$
\left\{\begin{array}{l}
\dot{x}=a y-m x+r, \\
\dot{y}=b x-n y+s .
\end{array}\right.
$$

Здесь $x(t)$ и $y(t)$ определяют расходы двух государств на вооружение, значения коэффициентов $a$ и $b$ описывают, как реагирует каждое государство на увеличение или уменьшение вооруженности другого государства. Ясно, что если одно государство увеличивает расходы на развитие науки и производства, связанные с военным потенциалом, то и другое государство также увеличит аналогичные расходы. Однако, в этом случае в игру вступает ограничивающий процесс - недовольство населения, начинаются демонстрации, давление на правительство конкурирующих политических партий, данное явление описывается коэффициентами $m$ и $n$. 
Каждое государство в конфронтации стремится показать свою силу с помощью демонстрации современного вооружения, проявляя агрессивность или миролюбивость. Именно положительные и отрицательные слагаемые $r$ и $s$ описывают меру миролюбивости и воинственности государств. Решением системы являются функции $x(t)$ и $y(t)$, определяемые для заданных начальных условий $x_{0}$ и $y_{0}$.

Возможны 3 случая поведения модели Ричардсона при $t \rightarrow \infty$ :

1. Бесконечная гонка вооружений: $x \rightarrow \infty$ и $y \rightarrow \infty$.

2. Взаимное разоружение: $x \rightarrow 0$ и $y \rightarrow 0$.

3. Равновесие вооружений: $x \rightarrow \bar{x}$ и $y \rightarrow \bar{y}$. Точка равновесия $(\bar{x}, \bar{y})$ находится на пересечении прямых

$$
\left\{\begin{array}{l}
a y-m x+r=0, \\
b x-n y+s=0 .
\end{array}\right.
$$

\section{2. Анализ модели Ричардсона «гонка вооружений»}

Из системы (1) видно, что на эволюцию модели «гонки вооружений» влияют значения шести параметров. Достаточно сложно выделить определяющее влияние недовольства населения или наличия оппозиции на развитие такой ситуации, когда вооружение сокращается. В данной работе мы смоделируем следующие случаи соотношений значений параметров.

Таблица 1. Соотношения значений параметров, определяющих эволюцию модели Ричардсона

\begin{tabular}{|l|c|c|c|}
\hline 1 & $(m n-a b)>0$ & $r>0$ & $s>0$ \\
\hline 2 & $(m n-a b)<0$ & $r>0$ & $s>0$ \\
\hline 3 & $(m n-a b)>0$ & $r<0$ & $s<0$ \\
\hline 4 & $(m n-a b)<0$ & $r<0$ & $s<0$ \\
\hline
\end{tabular}

Очевидно, что неравенство $(m n-a b)>0$ определяет случай, когда ограничивающие процессы более существенны, чем наращивание гонки вооружений государства в ответ на вооруженность противника. Знаки слагаемых $r$ и $s$ описывают миролюбивость (-) и воинственность $(+)$ государств. Каждое государство также может наращивать вооружение независимо от враждебности (реальной) других стран. Ясно, что мы должны рассмотреть различные комбинации знаков (см. табл. 1).

Случай 1. Смоделируем и исследуем эволюцию системы (1) для условия $(m n-a b)=0,5 ; a=1 ; b=1,5 ; m=2 ; n=1$, когда население государства против гонки вооружения, сильна оппозиция, однако, не смотря на активное сопротивление, оба государства имеют агрессивную внешнюю политику $(r=0,5, s=1)$. Заданы начальные условия $x_{0}=30, y_{0}=15$.

На рисунке $1(a)$ изображены графики расходов государств $x(t)$ и $y(t)$ на вооружение, которые построены на основе решений дифференциальных уравнений, полученных численно. Видно, что графики имеют точку пересечения, соответствующей равным значениям $x(t)$ и $y(t)$. Из начальных условий следует, что в начальный момент времени отношение $x_{0} / y_{0}=2$, то есть государство « $x »$ чувствует себя в безопасности и снижает расходы на вооружение, второе государство «у» наоборот наращивает гонку вооружений. В результате графики пересекаются, в этот момент времени два государства находятся в состоянии равновесия. Далее «у» продолжает наращивать вооружение, обеспечивая свою безопасность, однако этот процесс происходит непродолжительное время, поскольку государство «x» не достаточно агрессивно и продолжает снижать расходы на вооружение. Таким образом, при заданных значениях параметров оба государства снижают расходы 
на вооружение, такой результат исключает военный конфликт, ситуация является стабильной.

Случай 2. Смоделируем теперь эволюцию системы в случае, когда оба государства проводят агрессивную внешнюю политику для условия $(m n-a b)=-0,5$ и значений $a=2 ; b=1 ; m=1 ; n=1,5 ; r=0,5 ; s=1$. Заданы начальные условия $x_{0}=0, y_{0}=1$. Графики демонстрируют наращивание гонки вооружений для обоих государств, несмотря на существование точки равновесия (см. рис. 1 (б)). Естественно, что результатом такой эволюции будет военный конфликт.
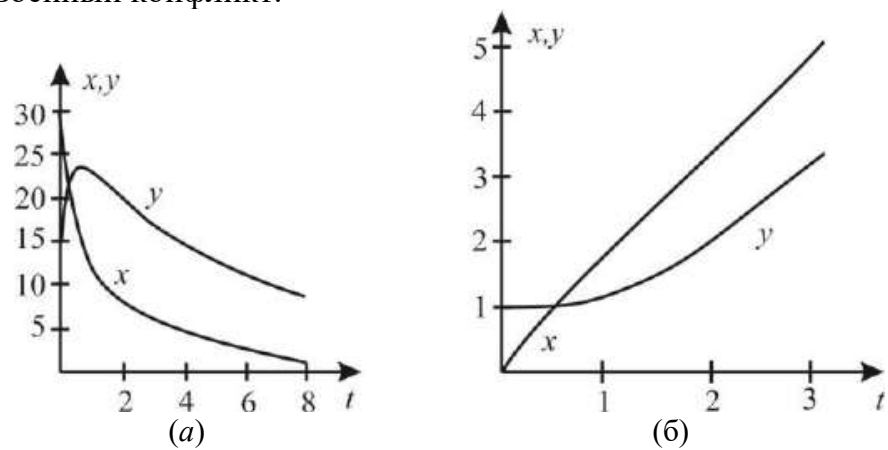

(б)

Рис. 1. Результаты численного решения системы дифференциальных уравнений модели Ричардсона: (a) случай $1,($ б) случай 2

Случай 3. Ситуация, которая фактически противоположна первой модели. Внешняя политика для обоих государств миролюбива, то есть имеем значения $r=-0,5 ; s=-1$. Результатом эволюции является разоружение обоих государств (рис. 2). В зависимости от начальных условий и заданных значений параметров мы можем ускорить или замедлить процесс разоружения.

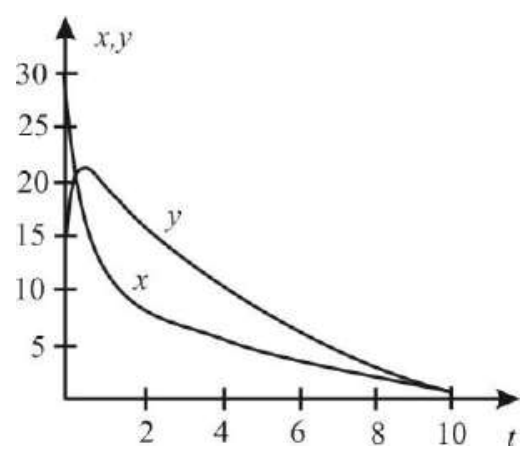

Рис. 2. Результаты численного решения системы дифференциальных уравнений модели Ричардсона: случай 3

Случай 4. Наконец исследуем влияние начальных условий на развитие ситуации, когда справедливо равенство $(m n-a b)=-0,5$, отрицательные значения $r=-0,5 ; s=-1$ задают миролюбивость внешней политики государств. Результаты численного решения системы (1) представлены в виде графиков на рисунках $3(a)$, равные начальные условия $x_{0}=6, y_{0}=6$ и (б), различные начальные условия $x_{0}=2, y_{0}=4$. Из анализа результатов вычислений следует, что именно начальные условия модели определяют эволюцию и предельный вариант гонки вооружений.

На рисунке 3 (a) представлен случай, в котором заданы равные начальные условия для обоих государств. Результатом этой модели является бесконечная гонка вооружений, и, следовательно, вооружённый конфликт или война. Для того чтобы выявить влияние 
начальных условий на эволюцию системы, рассмотрим различные значения для $x_{0}$ и $y_{0}$, оставшиеся параметры оставим прежними. Результаты численного расчёта представлены в виде графиков (рис. 3 (б)). Видно, что именно начальные условия определяют эволюционные траектории системы, так как соотношение $y_{0} / x_{0}=2$ приводит к взаимному разоружению государств, а равные начальные условия к бесконечной гонке вооружения при мирной политике государств.

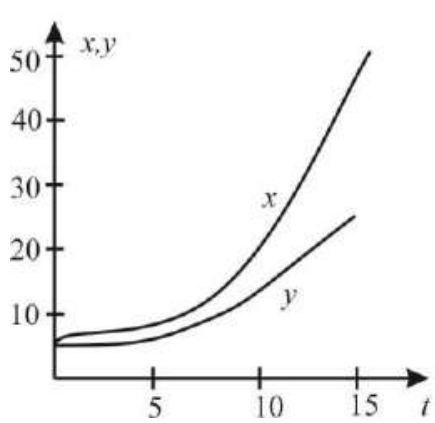

(a)

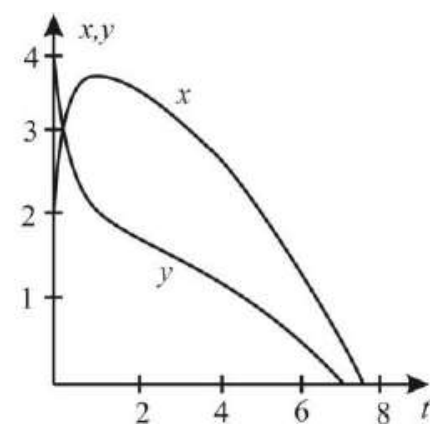

(б)

Рис. 3. Результаты численного решения системы дифференциальных уравнений модели Ричардсона (случай 4): (a) равные начальные условия; (б) начальные условия $y_{0} / x_{0}=2$

\section{3. Выводы}

Таким образом, сделаем следующие выводы.

1. Если ограничения на гонку вооружения, обусловленные недовольством населения в обоих государствах, достаточно велики $(m n-a b)>0$, то и в случае агрессивной и миролюбивой внешней политики происходит разоружение государств. В случае, когда $r<0$ и $s<0$, имеем случай взаимного полного разоружения: $x \rightarrow 0$ и $y \rightarrow 0$, а в случае, когда $r>0$ и $s>0$ имеем стабильную ситуацию. Это говорит о важности противодействия гонке вооружения со стороны населения и миролюбивой внешней политики государства.

2. Если ограничения на гонку вооружения малы $(m n-a b)<0$, то даже при наличии у государств «дружелюбной» внешней политики может произойти вооруженный конфликт. Однако, если одно из государств имеет современное мощное оружие (то есть его начальные условия значительно превосходят начальные условия противника), то оно чувствует себя в безопасности, и при миролюбивой внешней политике может произойти разоружение. То есть, если $r>0$ и $s>0$, то неминуемо происходит неограниченный рост гонки вооружений, а если $r<0$ и $s<0$, то ситуация зависит от начальных условий. О чём это говорит? Человечество может гарантировать отсутствие военных действий, активно выступая против гонки вооружений и агрессивной политики глав государств.

\section{2. Модифицированная модель Ланкастера}

\section{1. Постановка задачи}

Модель Ланкастера тесно связана с моделью Ричардсона и представляет собой простейшую модель борьбы двух противников - двух армий. В данной модели состояние системы описывается координатами точки $(x, y), x>0$ и $y>0$, где $x, y$ характеризуют численность армий государств - антагонистов. Для данной модели система дифференциальных уравнений имеет вид: 


$$
\left\{\begin{array}{l}
\dot{x}=-b y, \\
\dot{y}=-a x,
\end{array}\right.
$$

где мощность оружия армии $x$ задаётся коэффициентом $a$, а мощность оружия армии $y-$ коэффициентом $b$. Другими словами в системе дифференциальных уравнений первые слагаемые описывают скорость уничтожения армий, участвующих в войне или сражении: за единицу времени каждый солдат армии $x$ убивает $a$ солдат армии $y$, и, соответственно, каждый солдат армии $y$ убивает $b$ солдат армии $x$. Модель Ланкастера легко решается аналитически $a x^{2}-b y^{2}=$ const. Видно, что интегральной кривой является гипербола. Заданные начальные условия определяют ветвь гиперболы - эволюции системы. Система дифференциальных уравнений по-людоедски проста и не может претендовать на достоверное описание реального процесса, хотя на её основе можно понять предельное поведение системы. Ясно, что нужно усложнить систему, но не за счёт коэффициентов $a$ и $b$ [8], а за счёт дополнительных слагаемых в правых частях уравнений. В этом случае, моделируя различные ситуации хода войны или сражения, мы можем точно определить, какое именно слагаемое имеет решающее влияние на результат. В систему уравнений мы добавим слагаемое, моделирующее одновременную гибель солдат армий государств, участвующих в вооружённом конфликте. Такая ситуация возникает, когда оба противника используют биологическое и ядерное оружие, что характерно для современного мира. Также мы будем учитывать чрезвычайно важное влияние армий союзных держав. Таким образом, в систему уравнений мы включили такие глобальные слагаемые, которые могут определить ход эволюции человечества.

$$
\left\{\begin{array}{l}
\dot{x}=-b y-\beta x y+c, \\
\dot{y}=-a x-\varphi x y+e .
\end{array}\right.
$$

Слагаемые - $\beta x y$ и -фху в системе уравнений определяют уничтожение солдат обеих армий. С помощью слагаемых $c$ и $e$ мы задаём вступление в войну или сражение союзников. У данной модели существуют предельные случаи, которые чрезвычайно важны в моделировании $[10,11]$. Очевидно, что при выжидательной политике союзников, именно модель Лотки - Вольтерра задаёт описание конкурирующих процессов. Если нет глобальных явлений одновременного уничтожения солдат, эволюцию системы определяет модель Ланкастера. В предложенной модели мощность вооружения армий государств, заданная коэффициентами $a$ и $b$, влияет на значения коэффициентов $\beta$ и $\varphi$, так как чем более мощное и современное оружие использует армия, тем больше и своих солдат погибают в войне или сражении. Мы воспользуемся линейной зависимостью, которая адекватно описывает данное явление: $\beta=0,02 a$ и $\varphi=0,02 b$.

\section{2. Анализ модифицированной модели Ланкастера}

В данной статье рассмотрим два случая соотношений между начальными условиями $x_{0}$, $y_{0}$ и коэффициентами $a, b, c$ и $e$, представленными в системе дифференциальных уравнений (3). Если коэффициенты не равны, то предполагается, что их значения отличаются в два раза, то есть, если $a>b$, то $a / b=2$ (см. табл. 2).

Таблица 2. Комбинации коэффициентов для системы (3)

\begin{tabular}{|l|l|l|l|}
\hline 1 & $x_{0}=y_{0}$ & $c<e$ & $a>b$ \\
\hline 2 & $x_{0}<y_{0}$ & $c<e$ & $a>b$ \\
\hline
\end{tabular}


Случай 1 . Начальные условия равны $x_{0}=15, y_{0}=15$. Так как выполняется соотношения $a>b, b=0,3$, то $a=0,6$ и соответственно $\beta=0,02 \cdot 0,6=0,012, \varphi=0,02 \cdot 0,3=0,006$. Влияние союзников при моделировании системы (3) заданы в таблице 3.

Таблица 3. Влияние союзников для первого случая

\begin{tabular}{|c|c|}
\hline$c$ & $e$ \\
\hline 0,1 & 0,2 \\
\hline
\end{tabular}

Очевидно, что при равных начальных условиях каждая армия имеет преимущества по сравнению с противником: армия « $x »$ обладает мощностью оружия большей в два раза, а у армии «у» союзников в два раза больше. Что более важно при ведении военных действий для победы? Результаты численного расчёта представлены в виде графиков (см. рис. 4). Хотя начальные условия одинаковы для двух государств, победу одерживает армия «х», так как обладает более мощным оружием. Влияние союзников не так велико, чтобы изменить ход сражения (см. рис. $4(a)$ ). Чтобы кардинально сменить эволюцию системы (победа армии «у»), второму государству требуется в 15 раз увеличить влияние союзников, то есть существенно $(e=3)$. Отметим, что данное число получено экспериментально (см. рис. 4 (б)).

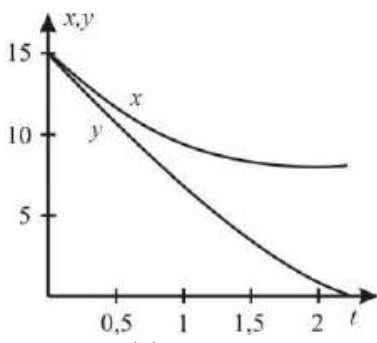

(a)

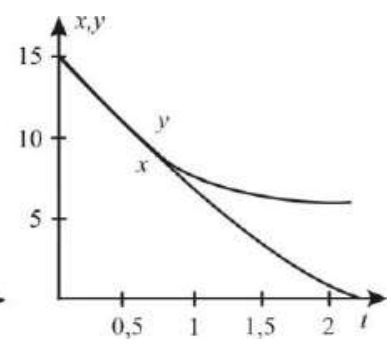

(б)

Рис. 4. Результаты численного решения системы дифференциальных уравнений модифицированной модели Ланкастера при равных начальных условиях

Случай 2. Моделируется ситуация, когда численность армии «у» в два раза больше численности армии «x» (см. табл. 4). Остальные значения используемых параметров такие же, как в случае 1. Проведём анализ расчётов на основе графиков (рис. 5).

Таблица 4. Начальные условия для второго случая

\begin{tabular}{|c|c|}
\hline$x_{0}$ & $y_{0}$ \\
\hline 4 & 8 \\
\hline
\end{tabular}

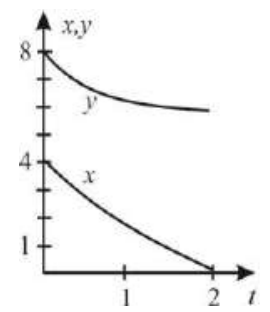

(a)

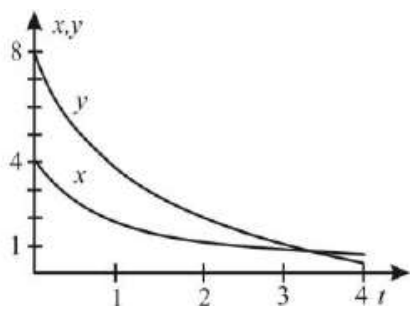

(б)

Рис. 5. Результаты численного решения системы дифференциальных уравнений модифицированной модели Ланкастера $(a=1,5)$ 
Численность армии «у» больше численности армии «x» в два раза, и несмотря на то, что мощность оружия армии «х» больше мощности оружия армии «у» также в два раза, армия «y» одерживает победу над армией «х». Что же делать в данной ситуации небольшим государствам с небольшой численностью, чтобы противостоять агрессору? Только наращивать гонку вооружений. Из рисунка 5 (б) следует, что, увеличив мощность оружия в 2,5 раза $(a=1,5)$ армия « $x »$ всё же уничтожит армию противника, конечно же, используя дальнодействующее высокоточное технологическое оружие.

Переломить ход войны в этой ситуации возможно за счёт более активного вступления союзников в вооружённое противостояние государств. Численный эксперимент даёт возможность определить значение $e=0,241$, при котором солдаты «y» одерживают победу. В данной модели мы используем значение $a=1,5$ и соответственно $\beta=0,03$. Численные результаты моделирования влияния союзников приведены в виде графиков на рисунке 6 . Увеличение численности союзников также приводит к кардинальному изменению результата военного конфликта.

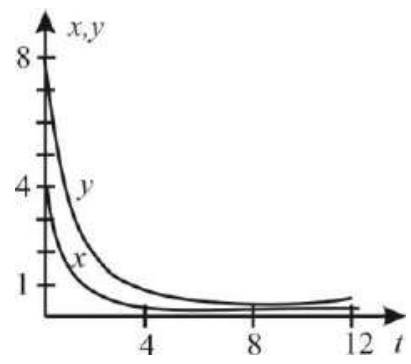

Рис. 6. Влияние союзников

\section{3. Сравненительный анализ модифицированной модели Ланкастера с классической моделью}

Для того чтобы отделить влияние дополнительных слагаемых в модифицированной модели Ланкастера, сравним её с классической моделью. Естественно использовать при таком анализе равные начальные условия. Значения остальных параметров приведены в таблице 5 .

Таблица 5. Классическая и модифицированная модели Ланкастера

\begin{tabular}{|c|c|c|c|c|c|c|c|c|}
\hline Начальные условия и параметры & $x_{0}$ & $y_{0}$ & $a$ & $b$ & $\beta$ & $\varphi$ & $c$ & $e$ \\
\hline Классическая модель & 4 & 8 & 1,5 & 0,3 & & & & \\
\hline Модифицированная модель & 4 & 8 & 1,5 & 0,3 & 0,03 & 0,006 & 0,1 & 0,2 \\
\hline
\end{tabular}

На рисунке 7 приведены графики, построенные на основе результатов численных расчётов для двух моделей Ланкастера: классической $(a)$ и модифицированной (б).

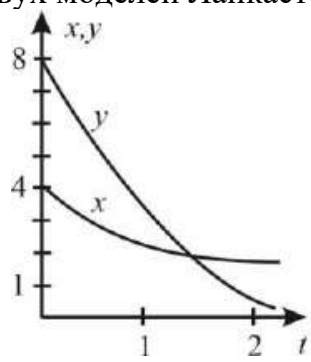

(a)

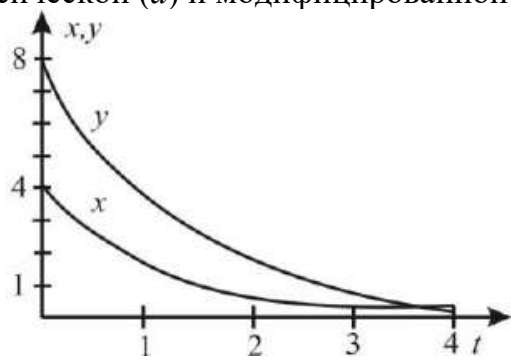

(б)

Рис. 7. Классическая и модифицированная модели Ланкастера - исход сражения 
Из анализа влияния дополнительных слагаемых на исход войны или сражения следует, что армия «x» одерживает победу и уничтожает солдат армии «y» в обоих случаях, так как значения параметров, учитывающие вступление в конфликт союзников, малы. Однако, естественно, в модифицированной модели переход в фазу победы осуществляется за бо́льшее время. Пусть теперь мы заложим влияние вступления в конфликт союзников в коэффициенты $a$ и $b$, которые определяют мощность оружия. Мы получим аналогичный результат, но уже не сможем понять, что конкретно повлияло на ход сражения. В таком случае невозможно прогнозировать результат войны между государствами, выделить влияние гонки вооружений, союзников. Начальные условия и значения параметров для классической модели Ланкастера приведены в таблице 6.

Таблица 6. Классическая модель Ланкастера

\begin{tabular}{|c|c|c|c|}
\hline$x_{0}$ & $y_{0}$ & $a$ & $b$ \\
\hline 4 & 8 & 1,5 & 0,36999 \\
\hline
\end{tabular}

Смоделированная модифицированная модель Ланкастера является детерминистической и обладает несомненным преимуществом по сравнению с другими моделями. В данной работе в системе дифференциальных уравнений мы учитываем наиболее глобальные и существенные слагаемые: мощность высокоточного и технологического оружия; вступление в эволюционную игру союзников. Динамическое моделирование позволяет определить значения и соотношения параметров, которые в определённый момент времени приводят к перелому войны или сражения. Очевидно, что если рассмотреть конкретное историческое событие, необходимо также учесть вероятностный характер случайных процессов, использовать более сложный математический аппарат, но в данной работе, как уже было отмечено, мы не ставим такую цель.

\section{3. Модифицированная модель динамики системы «хищник-жертва»}

\section{1. Постановка задачи}

Рассмотрим теперь классическую систему «хищник-жертва», в данной модели отсутствует конкуренция между объектами одного вида. Если в системе нет «хищников», то «жертвы» $x(t)$ плодятся пропорционально своей численности с коэффициентом прироста $k>0$, соответственно и хищные особи $y(t)$ без потребления добычи вымирают пропорционально своей численности с коэффициентом $l>0$. Численность жертв сокращается из-за хищников, а последние, напротив, плодятся. Этот процесс описывается хорошо известной системой дифференциальных уравнений:

$$
\left\{\begin{array}{l}
\dot{x}(t)=k x(t)-a x(t) y(t), \\
\dot{y}(t)=-l y(t)+b x(t) y(t) .
\end{array}\right.
$$

Здесь коэффициент $a$ определяет умерщвление жертв, когда хищники нападают на них, то есть хищники и жертвы пересекаются, это слагаемое прямо пропорционально величине $y x$. Коэффициент $b$ определяет переработку пищи в виде жертвы в биомассу хищника, хищники размножаются. Если биоценоз процветает, то есть условия биоценоза благоприятны, то возможны две ситуации: колебания популяций хищников и жертв; стабильное количество тех и других видов, хотя процесс поедания жертв хищниками осуществляется непрерывно. Однако, благоприятные условия, в действительности, наблюдаются не всегда (например, образование мёртвых зон). Естественно необходимо учесть некоторую поправку в классической модели.

В данной работе мы рассмотрим модель конкурирующих популяций с поправками $p_{1} x^{2}$ и $p_{2} y^{2}$ для жертв и хищников соответственно: 


$$
\left\{\begin{array}{l}
\dot{x}=k x-a x y+p_{1} x^{2}, \\
\dot{y}=-l y+b x y+p_{2} y^{2} .
\end{array}\right.
$$

где коэффициенты $p_{1}$ и $p_{2}$ определяют влияние внешних факторов на эволюцию системы как положительного, так и отрицательного характера, так как разнообразие условий среды может быть вредным или, напротив, приносить пользу живым организмам, содействовать выживанию или мешать размножаться. Экологические факторы делятся на абиотические (свойства неживой природы), биотические (виды влияния живых организмов друг на друга) и антропогенные (человеческая деятельность). Для начала биологической игры задаются начальные значения $x_{0}$ для жертв и $y_{0}$ для хищников. Эволюция игры и финал (в случае образования мертвой зоны) зависят от знаков и соотношений соответствующих коэффициентов. В правых частях уравнений системы дифференциальных уравнений выписаны слагаемые, определяющие влияние отдельных компонент на исход биологической игры. Важно также рассмотреть предельные случаи , когда образуются мёртвые зоны. Выбор дополнительных слагаемых в данной работе обусловлен следующими причинами:

1) нелинейный характер скорости размножения жертвы;

2) наличие конкуренции между жертвами за питание;

3) нелинейная гибель жертв за счет экологических катастроф;

4) нелинейный характер скорости выедания жертв хищниками;

5) наличие конкуренции между хищниками за поедание жертв;

6) нелинейный характер скорости размножения хищников.

Очевидно, значительное усложнение и увеличение числа дополнительных слагаемых затрудняет понимание эволюции системы Лотки - Вольтерра. В данной работе мы рассмотрим следующие глобальные случаи:

1) модель равного соотношения жертв и хищников за счёт размножения жертв и гибели хищников $(k=l)$ и за счёт поедания жертв хищниками $(a=b)$;

2) модель быстрого уменьшения жертвы по отношению к увеличению хищников, за счёт поедания жертв.

Кроме того, на систему влияют нелинейные дополнительные слагаемые, которые, возможно, определят гибель экосистемы. Отметим, что наличие нелинейности в системе дифференциальных уравнений позволяет учесть также принцип конкурентного исключения Г.Ф. Гаузе, так как и жертвы, и хищники жёстко конкурируют между собой за питание и поедание жертв соответственно.

\section{2. Модель равного соотношения жертв и хищников за счёт размножения жертв и гибели хищников $(k=l)$ и за счёт поедания жертв хищниками $(a=b)$}

Рассмотрим следующие комбинации значений параметров системы 5 (см. табл. 7): равное соотношение жертв и хищников за счёт размножения жертв и гибели хищников $(\mathrm{k}=1)$ и за счёт поедания жертв хищниками $(\mathrm{a}=\mathrm{b})$ с учётом нелинейного характера скорости размножения жертв и хищников (знак + ) и их гибели при экологических катастрофах и наличия конкуренции за питание (знак -).

Случай 1. Рассмотрим следующую ситуацию: коэффициенты прироста жертв и гибели хищников равны; условия обитания для хищников и жертв - благоприятны, начальные условия - число хищников в два раза меньше, чем жертв (см. табл. 8).

Результаты вычислений представлены на рисунке 8(a). Поведение системы практически совпадает с поведением классической системы Лотки - Вольтерра. Из рисунка видно, что даже при положительном влиянии внешней среды, способствующей нелинейному размножению, популяция не сразу может восстановить численность. Данный процесс имеет периодический характер. 
Таблица 7. Комбинации значений параметров для системы (1)

\begin{tabular}{|c|c|c|c|c|}
\hline 1. & $k=l$ & $a>b$ & $p_{1}>0$ & $p_{2}>0$ \\
\hline 2. & $k=l$ & $a>b$ & $p_{1}<0$ & $p_{2}<0$ \\
\hline 3. & $k>l$ & $a=b$ & $p_{1}>0$ & $p_{2}>0$ \\
\hline 4. & $k>l$ & $a=b$ & $p_{1}<0$ & $p_{2}>0$ \\
\hline 5. & $k>l$ & $a=b$ & $p_{1}<0$ & $p_{2}<0$ \\
\hline 6. & $k<l$ & $a=b$ & $p_{1}>0$ & $p_{2}<0$ \\
\hline 7. & $k<l$ & $a=b$ & $p_{1}<0$ & $p_{2}<0$ \\
\hline
\end{tabular}

Таблица 8. Комбинации значений параметров для случая 1

\begin{tabular}{|c|c|c|c|c|c|c|c|}
\hline \multicolumn{2}{|c|}{ Начальные условия } & \multirow{2}{*}{$a$} & $b$ & $k$ & $l$ & $p_{1}$ & $p_{2}$ \\
\cline { 1 - 5 } & $y_{0}$ & & & & & & \\
\hline 100 & 50 & 0,04 & 0,02 & 0,3 & 0,3 & 0,0004 & 0,0004 \\
\hline
\end{tabular}
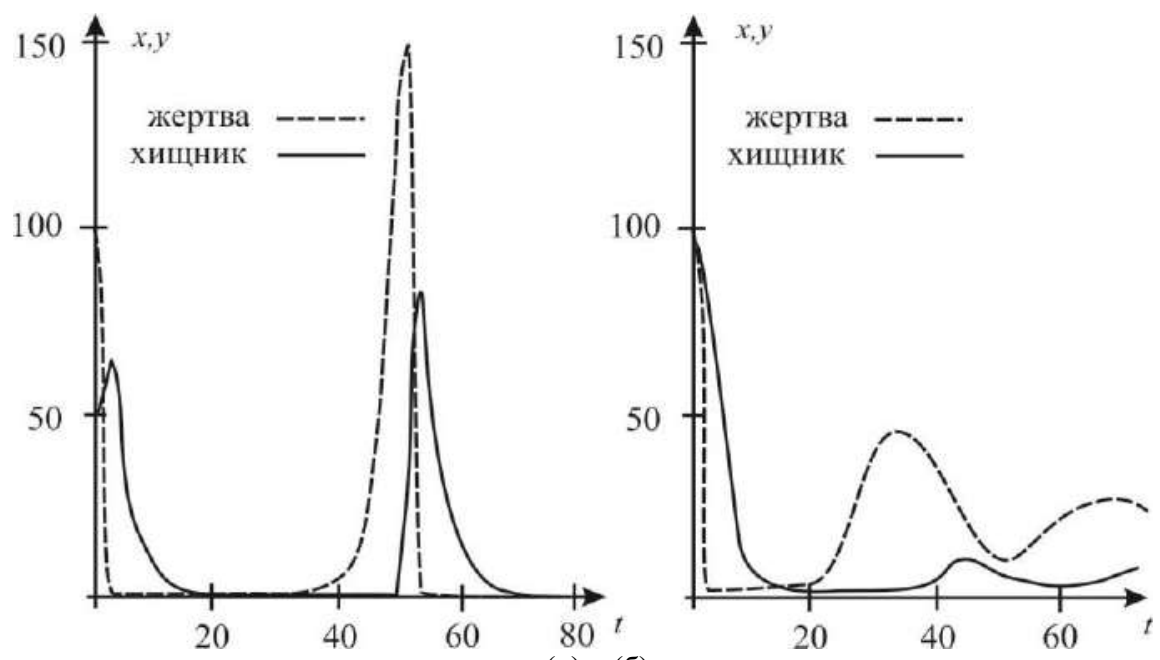

(a) (б)

Рис. 8. Эволюция системы (5): (a) - условия биоценоза благоприятны, случай 1 ;

(б) - условия биоценоза неблагоприятны, случай 2

Случай 2. Ситуация, при которой коэффициенты размножения жертв и гибели хищников равны, условия жизнедеятельности оказывают негативное влияние на развитие популяций, как для жертв, так и для хищников, $p_{1}=p_{2}=-0,006$ (см. табл. 7).

Из рисунка 8 (б) видно, что такое влияние с течением времени приводит к затухающим колебаниям, численность видов уменьшается. Отметим, что в начальные моменты времени поведение модифицированной модели совпадает с поведением классической модели Лотки - Вольтерра.

С течением времени для классической модели характерен рост численности жертв. Следовательно, даже незначительное негативное влияние на биоценоз приводит к сокращению численности и жертв, и хищников.

Случай 3. Ситуация, при которой коэффициент размножения жертв выше, по сравнению с коэффициентом смертности хищников. Условия обитания способствуют благополучному развитию обеих популяций (см. табл. 9). 
Таблица 9. Комбинации значений параметров для случая 3

\begin{tabular}{|c|c|c|c|c|c|c|c|}
\hline \multicolumn{2}{|c|}{ Начальные условия } & \multirow{2}{*}{$a$} & $b$ & $k$ & $l$ & $p_{1}$ & $p_{2}$ \\
\cline { 1 - 5 } & $y_{0}$ & & & & & & \\
\hline 100 & 100 & 0,02 & 0,02 & 0,7 & 0,3 & 0,0006 & 0,0006 \\
\hline
\end{tabular}

Видно (см. рис. $9(a)$ ), что число жертв идёт на спад, это связано с резким ростом численности хищных видов. После этого жертвы довольно долго восстанавливаются, что приводит к резкому уменьшению числа хищников, которые терпят недостаток в пище. В то время как вымирают хищники, жертвы начинают активно размножаться. Мы наблюдаем колебательный процесс.

Случай 4. Ситуация, при которой коэффициент роста жертв больше, чем коэффициент гибели хищников. Условия благоприятны исключительно для последних, жертвы терпят кризис, $p_{1}=-0,006, p_{2}=0,006$. Значения $x_{0}, y_{0}$ для обоих видов в начальный момент времени равны. Результаты вычислений для данного случая представлены на рис. 9 (б).

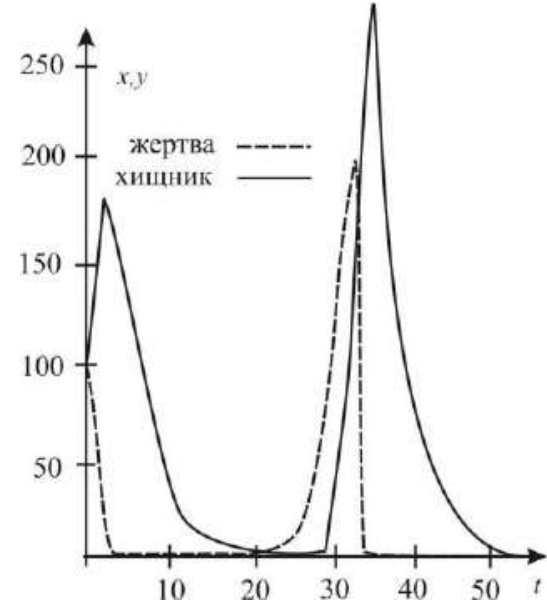

(a) (б)

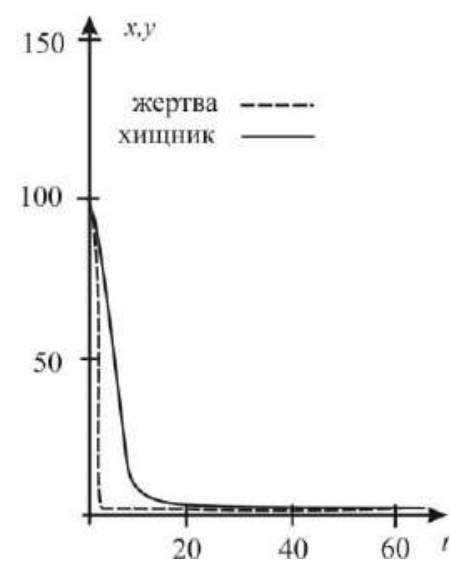

(б)

Рис. 9. Эволюция системы (5): (a) - условия биоценоза благоприятны, случай 3 ;

(б) - условия биоценоза неблагоприятны для жертв, случай 4

Видно, что жертвы достаточно быстро прекращают своё развитие, их численность достигает нуля. Популяция же хищников также вымирает, но более медленно. Популяции не успевают размножаться, образуется так называемая мёртвая зона.

Случай 5. Ситуация, при которой коэффициент роста жертв больше, чем коэффициент гибели хищных видов $k=0,8, l=0,6$. Условия среды неблагоприятны и для жертв, и для хищников, $p_{1}=p_{2}=-0,006$, начальные условия те же самые.

Из рисунка 10(a) видно, что характер эволюции системы носит колебательный характер, за счёт более высокого коэффициента рождаемости жертв система выживает, но амплитуда колебаний падает из-за неблагоприятных условий. Что делать в этом случае? Конечно - улучшить условия существования жертв, возможно в этом случае, экосистема выживет. 

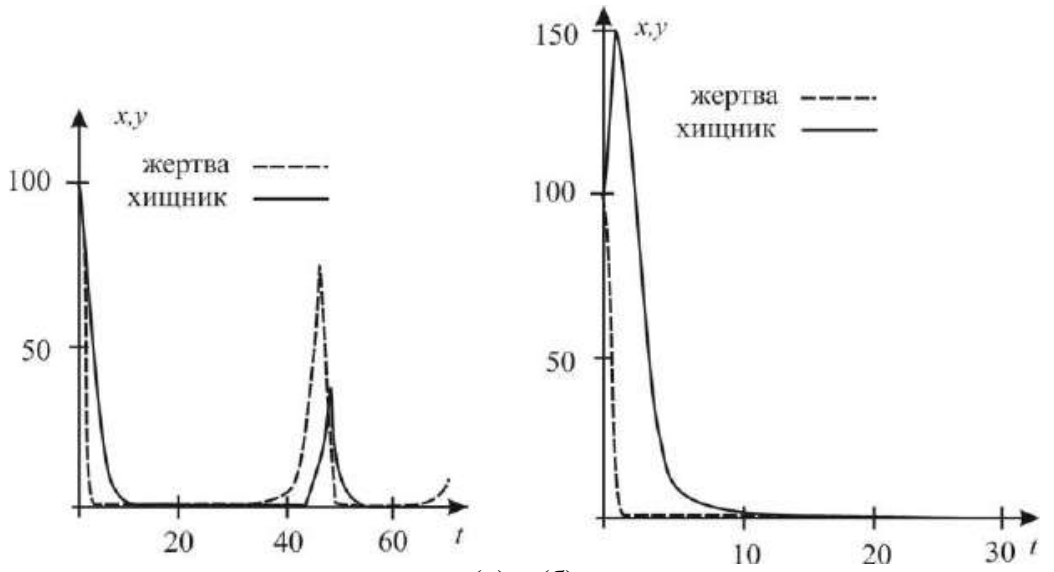

(a) (б)

Рис. 10. Эволюция системы (5): (a) - условия биоценоза неблагоприятны, случай 5; (б) - условия биоценоза благоприятны, случай 6

Случай 6. Ситуация, при которой коэффициент роста жертв меньше, чем коэффициент гибели хищных видов $k=0,2, l=0,6$. Условия среды благоприятны и для жертв, и для хищников, $p_{1}=0,0006, p_{2}=0,0008$, начальные условия те же самые.

Из рисунка 10(б) видно, что число жертв резко идёт к снижению, хищники изначально начинают активно размножаться. Далее численность популяций уменьшается, так как жертв становится меньше, и хищникам нечем питаться. Коэффициент смертности выше рождаемости, что отрицательно влияет на систему. Популяции не в состоянии продолжить своё существование, несмотря на благоприятные условия. Таким образом, в этом случае необходимо повлиять на увеличение рождаемости жертв.

Случай 7. Здесь мы рассмотрим аналогичный случай, но при отрицательном влиянии дополнительных слагаемых $p_{1}=-0,006, p_{2}=-0,008, k=0,4, l=0,6$. В этом случае, несмотря на увеличение рождаемости жертв, оба вида также погибают, причём практически сразу и жертвы, и хищники гибнут, так как влияют отрицательные факторы.

Таким образом:

1. Влияние дополнительных факторов на эволюцию биоценоза является существенным, положительные значения коэффициентов вызывают процветание биоценоза, отрицательные же значения приводят к гибели и жертв, и хищников. Чтобы контролировать реальный биоценоз и не допускать образование мёртвых зон, нужно, по крайней мере, способствовать значительному размножению жертв, что приводит соответственно к увеличению численности хищников.

2. Только достаточно большие коэффициенты размножения жертв, которые к тому же должны быть больше по сравнению с коэффициентами вымирания хищников, могут перебороть нелинейную гибель видов, обусловленную экологическими катастрофами.

\section{3. Модель быстрого уменьшения численноси жертвы по отношению к увеличению численности хищников за счёт поедания жертв}

Мы рассмотрим случаи когда $(a / b>1)$, то есть коэффициент убийства жертв выше, чем коэффициент преобразования хищниками биомассы жертв в свою биомассу, и $(a / b<1)$, то есть хищники быстро размножаются за счёт поедания жертв, их количество быстро увеличивается. Кроме того, нелинейные эффекты могут менять ход эволюции системы. Смоделируем случаи комбинаций значений параметров системы (5) в таблице 10. 
Таблица 10. Комбинации значений параметров для системы (5)

\begin{tabular}{|c|c|c|c|c|}
\hline 1. & $k=l$ & $a / b>1$ & $p_{1}>0$ & $p_{2}>0$ \\
\hline 2. & $k=l$ & $a / b>1$ & $p_{1}<0$ & $p_{2}<0$ \\
\hline 3. & $k<l$ & $a / b>1$ & $p_{1}>0$ & $p_{2}>0$ \\
\hline 4. & $k<l$ & $a / b>1$ & $p_{1}<0$ & $p_{2}<0$ \\
\hline 5. & $k>l$ & $a / b<1$ & $p_{1}>0$ & $p_{2}>0$ \\
\hline 6. & $k<l$ & $a / b<1$ & $p_{1}<0$ & $p_{2}<0$ \\
\hline
\end{tabular}

Случай 1. Ситуация, при которой начальные условия и коэффициенты размножения жертв и гибели хищников равны, $x_{0}=100, y_{0}=100, k=l=0,2$, условия среды благоприятны. Число жертв резко уменьшается при нападении хищников, что может быть вызвано их агрессивностью, обусловленной нелинейным характером размножения (см. табл. 11). На рисунке 11 виден сначала рост хищников, жертвы очень быстро погибают. Далее мы наблюдаем вымирание популяций, несмотря на положительные коэффициенты нелинейных слагаемых. Если же рассмотреть отрицательные коэффициенты нелинейных слагаемых, то гибель популяций начинается в начальный момент времени (случай 2). Далее характер эволюции аналогичен.

Таблица 11. Использованные значения параметров для случая 1

\begin{tabular}{|c|c|c|c|}
\hline$a$ & $b$ & $p_{1}$ & $p_{2}$ \\
\hline 0,5 & 0,3 & 0,0003 & 0,0005 \\
\hline
\end{tabular}

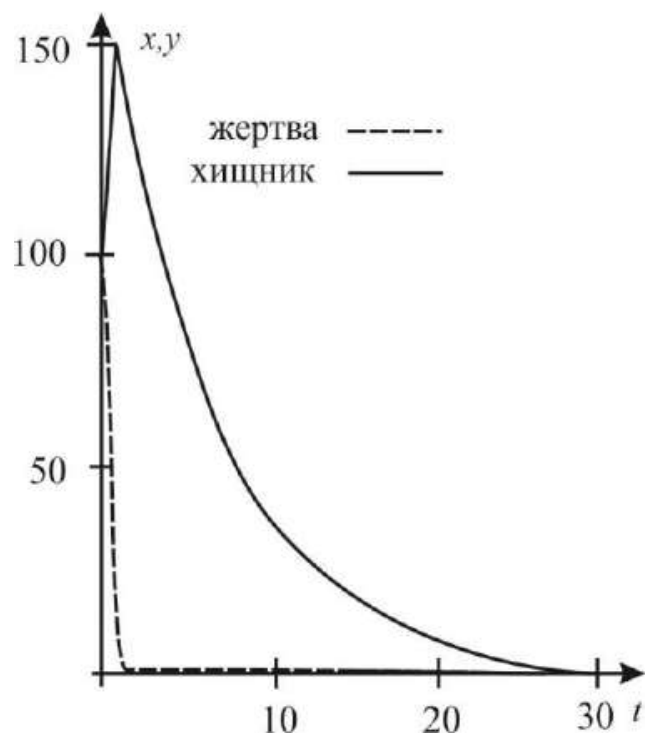

Рис. 11. Эволюция системы (5): условия биоценоза благоприятны, случай 1

Случай 3. Ситуация, при которой в начальный момент времени численность жертв в два раза больше, чем хищников, $x_{0}=100, y_{0}=50$, рождаемость жертв ниже по сравнению с гибелью хищников, $k=0,02, l=0,04$, условия благоприятные для обоих видов (см. табл. 12). 
Таблица 12. Использованные значения параметров для случая 3

\begin{tabular}{|c|c|c|c|}
\hline$a$ & $b$ & $p_{1}$ & $p_{2}$ \\
\hline 0,5 & 0,3 & 0,0004 & 0,0003 \\
\hline
\end{tabular}

На рисунке 12 представлены результаты вычислений. Число жертв резко идёт на спад до нуля. За счёт благоприятных условий хищники сначала активно размножаются и далее они продолжают выживать (продолжительность жизни увеличивается) достаточно долго, численность их уменьшается медленно, что значительно отличается от рассмотренных ранее случаев.

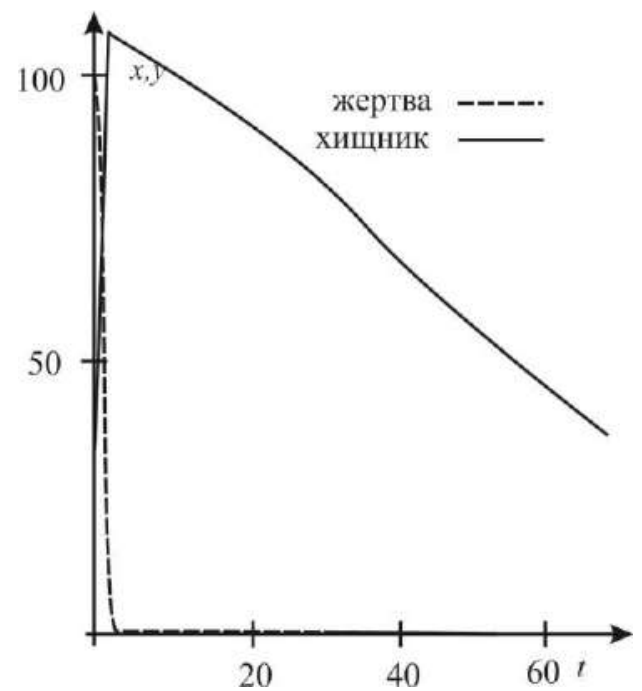

Рис. 12. Эволюция системы (5): условия биоценоза благоприятны, рождаемость жертв низкая, случай 3

Случай 4. Отличие данного случая заключается лишь в том, что условия неблагоприятны $p_{1}=-0,0004, \quad p_{2}=-0,0003$, поэтому происходит быстрый спад численности хищников до нуля.

Случай 5. Ситуация, при которой в начальный момент времени численность жертв в два раза больше, чем хищников, $x_{0}=100, y_{0}=50$, скорость размножения жертв гораздо выше, чем скорость гибели хищников, $k=0,4, l=0,2$. Условия среды соответствуют благоприятному нелинейному размножению для первых и вторых видов (см. табл. 13).

Таблица 13. Использованные значения параметров для случая 5

\begin{tabular}{|c|c|c|c|}
\hline$a$ & $b$ & $p_{1}$ & $p_{2}$ \\
\hline 0,2 & 0,3 & 0,0005 & 0,0007 \\
\hline
\end{tabular}

В данной модели также учитывается, что число погибших хищников резко сокращается по сравнению с их приростом за счёт обильного поедания жертв. На рисунке 13 видно, что сначала хищники активно размножаются, но из-за низкой рождаемости жертв и нехватки питания погибают, несмотря на благоприятные условия. 


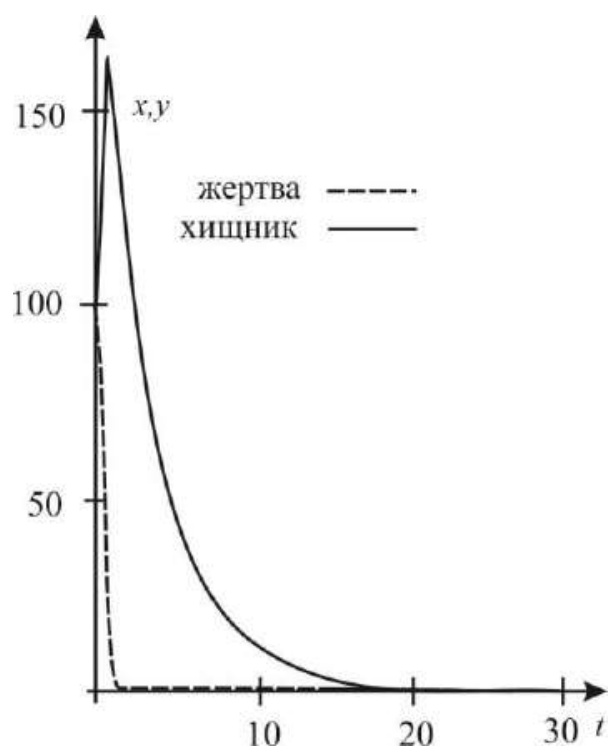

Рис.13. Эволюция системы (5): условия биоценоза благоприятны, случай 5

Случай 6. Ситуация, при которой в начальный момент времени численность жертв в два раза больше, чем хищников, $x_{0}=100, y_{0}=50$, скорость роста численности жертв уменьшается по сравнению со скоростью гибели хищников. Нелинейные дополнительные слагаемые отрицательны. В данной модели также учитывается, что число погибших хищников резко сокращается по сравнению с их приростом за счёт обильного поедания жертв (см. табл. 14).

Таблица 14. Использованные значения параметров для случая 6

\begin{tabular}{|c|c|c|c|c|c|}
\hline$a$ & $b$ & $k$ & $l$ & $p_{1}$ & $p_{2}$ \\
\hline 0,3 & 0,6 & 0,4 & 0,8 & $-0,004$ & $-0,007$ \\
\hline
\end{tabular}

В этом случае также наблюдается резкое уменьшение количества обоих видов, даже возможность обильного питания не может перебороть низкую рождаемость жертв, высокую смертность хищников и отрицательное влияние нелинейных факторов.

\section{Заключение}

Для того чтобы конфронтация государств не привела к началу войны необходимо учитывать в моделях Ричардсона и Ланкастера следующие условия:

1) активность населения государств для моделирования ограничения гонки вооружения;

2) миролюбивость внешней политики;

3) в случае начала войны, наличие сильных союзников.

Численный анализ с учётом интерактивности (возможности изменения параметров) даёт возможность визуализировать результаты и показывать текущую ситуацию. На его основе мы можем делать прогнозы на будущее и предотвратить достаточно реальную катастрофу - уничтожение человечества.

Рассмотренная модифицированная достаточно простая модель «хищник-жертва» описывает эволюцию системы с конкурирующими процессами и нелинейным влиянием как внешних, так и внутренних факторов, и даёт возможность явно предсказать, а значит, 
избежать появление мёртвых зон в природе. Преимущество данной модели состоит в том, что нелинейные слагаемые описывают практически весь набор возможных случаев позитивного и негативного влияния окружающей среды. Различные комбинации параметров системы дифференциальных уравнений определяют эволюцию биоценоза.

На основе проведённых численных расчётов и анализа результатов решения модифицированной системы Лотки - Вольтерра с различными параметрами можно сделать выводы.

Для выживания экосистемы необходимы следующие условия:

1) достаточно большие коэффициенты размножения жертв;

2) коэффициенты размножения жертв должны быть больше коэффициентов гибели хищников;

3) наличие позитивного нелинейного характера скорости размножения жертв. Только в этом случае мы наблюдаем колебательный характер эволюции биоценоза.

В случае экологических катастроф биоценоз неминуемо погибает. Для его восстановления необходимо значительно повысить скорость размножения жертв. Тогда при незначительных отрицательных нелинейных слагаемых всё-таки возможно восстановление биоценоза.

\section{Литература}

[1] Вольтерра В. Математическая теория борьбы за существование / М.: Наука, 1976.

[2] Kingsland S. Alfred J. Lotka and the origins of theoretical population ecology / Proceedings of the National Academy of Sciences Aug 2015. Vol. 112, № 31. P. 9493-9495.

[3] Никольский М.С. Об управляемых вариантах модели Л. Ричардсона в политологии / Тр. ИММ УрО РАН, 2011. Том 17, № 1. С 121-128.

[4] Братусь А.С., Новожилов А.С., Платонов А.П. Динамические системы и модели в биологии / М.: ФИЗМАТЛИТ, 2009.

[5] Ризниченко Г.Ю., Рубин А.Б. Математические методы в биологии и экологии. Биофизическая динамика продукционных процессов / М.: Юрайт, 2018.

[6] Эдвардс Ч.Г. Дифференциальные уравнения и краевые задачи: моделирование и вычисление с помощью Mathematica, Maple и MATLAB. 3-е издание / М.: Вильямс, 2008.

[7] Бродский Ю.И. Лекции по математическому и имитационному моделированию / Москва-Берлин: Директ медиа, 2015.

[8] Арнольд В.И. «Жёсткие и мягкие математические модели / МЦНМО. 2004.

[9] Возмищева Т.Г., Рудина Ю.И. Исследование модифицированной модели войны или сражения на основе модели Лотки - Вольтерра, качественный и численный анализ // Приборостроение в XXI веке - 2019. Интеграция науки, образования и производства. Сборник материалов XV Всероссийской научно-технической конференции. Ижевск, 2019. C. 314-322.

[10] Vozmishcheva T. The limit passage of space curvature in problems of celestial mechanics with the generalized Kepler and Hooke potentials // Astrophysics and Space Science. 2016. Vol. 361, № 9. P. 1-7.

[11]Возмищева Т.Г. Траекторная эквивалентность задачи двух центров в плоском пространстве, в пространстве Лобачевского и на сфере: предельный переход (часть 1) // Ижевск: Вестник ИжГТУ имени М.Т. Калашникова. 2015. Т. 18, № 2. С. 112 -116. 


\title{
The Modified Model of War or Battle and Arms Race on the Base of the Lotka - Volterra Model as the Model of Confrontation Between States: Numerical and Qualitative Analysis
}

\author{
T.G. Vozmishcheva
}

\section{Kalashnikov Izhevsk Technical University}

The modified models with the competing processes: the Richardson arms race model, the Lanchester war or battle model, the predator-prey model, induced by the Lotka - Volterra model are studied in the paper. The qualitative analysis and also numerical calculation of evolutionary trajectories of system for various values of parameters is carried out. The comparative analysis of the classical and modified models on the base of the constructed graphs of solutions of the system of differential equations is presented.

The offered modified Richardson and Lanchester models possess the undoubted advantage in comparison with other models. In the paper in the system of the differential equations, we consider the most global and essential terms: the power of high-precision and technological weapons; the allies entry into the evolutionary game. Dynamic simulation allows us to define the values and relations of parameters which lead to the war or battle turn at some point in time.

Let's note that in the paper the real concrete historical events are not considered since mathematical models are always restricted: it is impossible to take into account random factors which are connected with stochastic processes and have a probabilistic character.

Solutions of the system of the differential equations which model the nonlinear influence of both external and internal factors on an ecosystem are received.

Various parameters of the system of differential equations which cover practically all the set of possible beneficial and adverse effect on evolution of a biocenosis are considered. The conditions for which at insignificant negative nonlinear terms the restoration of a biocenosis is possible are presented.

Keywords: Lotka - Volterra model; Lanchester war or battle model; modified Lanchester model; Richardson arms race model; modified predator-prey model

Reference for citation: Vozmishcheva T.G. The Modified Model of War or Battle and Arms Race on the Base of the Lotka - Volterra Model as the Model of Confrontation Between States: Numerical and Qualitative Analysis // Information Society: Education, Science, Culture and Technologies of the Future. Vol. 4 (Proceedings of the XXIII International Joint Scientific Conference«Internet and ModernSociety»,IMS-2020, St. Petersburg, June 17-20, 2020). - St. Petersburg: ITMO University, 2020. P. 72 - 91. DOI: 10.17586/2587-8557-2020-4-72-91

\section{References}

[1] Vol'terra V. Matematicheskaja teorija bor'by za sushchestvovanie [The mathematical theory of struggle for existence]. Moscow, Science, 1976, 286 p. (in Russian).

[2] Kingsland S. Alfred J. Lotka and the origins of theoretical population ecology / Proceedings of the National Academy of Sciences Aug 2015. Vol. 112, № 31. P. 9493-9495.

[3] Nikol'skij M.S. Ob upravlyaemykh variantakh modeli L. Richardsona v politologii [On the controllable variants of Richardson's model in political science] / Tr. IMM UrO RAN, 2011. Vol 17, № 1. P. 121-128 (in Russian).

[4] Bratus' A.S., Novozhilov A.S., Platonov A.P. Dinamicheskie sistemy i modeli v biologii [Dynamical systems and models in biology] / M.: FIZMATLIT, 2009 (in Russian).

[5] Riznichenko G.Yu., Rubin A.B. Matematicheskie metody $v$ biologii i ekologii. Biofizicheskaya dinamika produktsionnykh protsessov [Mathematical methods in biology 
and ecology. Biophysical dynamics of productional processes] / M.: Yurayt, 2018 (in Russian).

[6] Jedvards Ch.G. Differencial'nye uravnenija i kraevye zadachi: modelirovanie i vychislenie s pomoshch'ju Mathematica, Maple i MATLAB. 3-e izdanie [Differential equations and boundary problems: modeling and calculation by means of Mathematica, Maple and MATLAB]. Moscow, Publishing House Vil'jams, 2008, 1094 p.

[7] Brodskij Ju.I. Lekcii po matematicheskomu i imitacionnomu modelirovaniju [Lectures on mathematical modeling and simulation]. Moscow, Berlin: Direct media, 2015, 240 p. (in Russian).

[8] Arnol'd V.I. «Zhestkie» i «mjagkie» matematicheskie modeli [«Hard» and «Soft» mathematical models]. Moscow Center for Continuous Mathematical Education, 2004. 32 p. (in Russian).

[9] Vozmishcheva T.G., Rudina Yu.I. Issledovanie modificirovannoj modeli vojny ili srazhenija na osnove modeli Lotki - Vol'terra, kachestvennyj i chislennyj analiz [The study of the modified model of war or buttle on the base of the Lotka - Volterra model, the qualitative and numerical analysis]. Priborostroenie v XXI veke - 2019. Integracija nauki, obrazovanija i proizvodstva. Sbornik materialov XV Vserossijskoj nauchno-tehnicheskoj konferencii [Proc. Instrumentation Engineering in the XXI Century. Integration of Science, Education and Production]. Izhevsk, 2019. P. 314-322 (in Russian).

[10] Vozmishcheva T. The limit passage of space curvature in problems of celestial mechanics with the generalized Kepler and Hooke potentials // Astrophysics and Space Science. 2016. Vol. 361, № 9. P. 1-7.

[11] Vozmishcheva T.G. Traektornaya ekvivalentnost' zadachi dvukh tsentrov v ploskom prostranstve, $\mathrm{v}$ prostranstve Lobachevskogo i na sfere: predel'nyy perekhod (chast' 1) [Trajectory equivalence of the two-center problem in the flat space, in the Lobachevsky space and on a sphere: the limit passage (part 1)]. Vestnik IzhGTU imeni M.T. Kalashnikova, 2015, Vol. 18, № 2, P. $112-116$ (in Russian). 